\title{
Prevalence of Periodontitis in Hemodialysis Patients
}

\author{
Dr. Nandini Manjunath, M.D.S. ${ }^{1,}$ Dr. Sahana, M.D.S. ${ }^{2,}$ Dr. Pallavi Nanaiah ${ }^{2}$ \\ Professor and HOD, Dept. Of Periodontics A.J. Institute Of Dental Sciences NH-66, Kuntikana, Mangalore- \\ 575004 Karnataka, India \\ Assistant Professor, Dept. Of Periodontics A.J. Institute Of Dental Sciences NH-66, Kuntikana, Mangalore- \\ 575004 Karnataka, India \\ Assistant Professor, Dept. Of Periodontics, Dayanand Sagar College of dental sciences Bangalore Karnataka, \\ India
}

\begin{abstract}
Aims- Periodontal disease, a chronic bacterial infection of the oral cavity is a novel risk factor for various systemic diseases. Among the systemic diseases, end stage renal disease has been shown to affect not only the general health of the patient but also oral and periodontal health. This study was conducted to gain an insight on the influence of renal dialysis on periodontal health.

Materials and method- 234 patients undergoing renal dialysis (60\% male, $40 \%$ female) were included in the study. The study group was divided into 4 age groups confounding systemic evaluation was conducted. Periodontal disease status was measured by CPITN. The collected data was analysed using SPSS.Inc Chicago ,USA (11.5) software.

Results- Prevalence of moderate to severe gingivitis and moderate periodontitis were seen in renal dialysis of patients.

Conclusion- The deteriorating general health causes negligence of oral health. The population needs comprehensive oral and periodontal care in consultation with nephrologist and oral health professionals.
\end{abstract}

Keywords - chronic renal disease, haemodialysis, periodontitis, CPITN index

\section{Introduction}

Chronic renal failure is defined as the progressive and usually irreversible decline of the glomerular infiltration rate leading to an increase of serum creatinine and blood urea nitrogen levels. The most common cause of chronic renal failure are hypertension, diabetes mellitus, chronic glomerulonephritis, uropathy and autoimmune diseases. ${ }^{1}$

Periodontitis is a bacteria driven chronic inflammatory disease that destroys the connective tissue and bone that supports the teeth and represents a potential source of episodes of bacteraemia especially in immune compromised patients.

The incidence of end stage renal disease is increasing and patients receiving renal replacement therapy including haemodialysis, peritoneal dialysis or renal transplantation comprise a large group of dental patients with increased levels of plaque, calculus and gingival inflammation and possible increased prevalence and severity of destructive periodontal disease. The presence of undiagnosed periodontitis may have significant effects on the medical management of the end stage renal disease patients (ESRD). Periodontitis has been found to contribute to systemic inflammatory burden with increase in C- reactive proteins and its effect on systemic health. ${ }^{2}$ Literature on research has shown $100 \%$ prevalence of periodontal disease in these patients, compared to the healthy individuals $\mathrm{s}^{3,4}$.

Multivariate regression models have been developed to aid in early identification of patients at high risk for chronic kidney disease including age, race, ethnicity, gender, education, lower income, smoking, diabetes, hypertension, anaemia, peripheral vascular disease, high cholesterol, body mass index, annual physician visit and hospitalization. ${ }^{5,6,7,8}$ The present study was conducted to evaluate the periodontal status in patients undergoing renal dialysis.

\section{Study Population}

\section{Materials And Method}

A total sample of 234 subjects who were undergoing haemodialysis were selected from Mangalore city. Four major renal care centres (A.J.Health and Reseach center, KMC hospital, Yenopoya hospital, Mangalore Kidney Foundation) in the city were included with unrelated subjects of either sex, age and socioeconomic status.

The subjects completed personal medical and dental history questionnaire. These subjects signed informed consent after being advised the nature of the study. The study was approved by ethical committee and Research at RGUHS ( Helsinki Declaration 1975 modified in 1983 ). 
After random selection of subjects, they were divided into 4 age group of 29-34, 35-44,45-64, 6575,>75years. We choose comprehensive demographic and clinical variables as potential determinants of chronic renal disease, based on the literature. The variables included age, sex occupation, family history, H/O other systemic diseases, medication taken, no.of dialysis undergone, type of dialysis, H/O renal transplant, personal history included oral hygiene status and loss of teeth was assessed. Periodontal examination included CPITN (Community Periodontal Index Of Treatment Needs).

\section{INCLUSION CRITERIA}

1) Age $\geq 29$ years

2) Glomerular filtration rate more than $60 \mathrm{ml} / \mathrm{min}$

\section{EXCLUSION CRETERIA}

1. History of smoking.

2. Periodontal therapy within 6 months.

3. History of receiving antibiotic therapy within the period of 6 months.

\section{Statistical Analysis}

The data collected were analysed using SPSS version 11.5, statistical package for window ( SPSS. Inc Chicago, USA). Periodontal status were assessed using ANNOVA, to evaluate the difference among groups. Chi- square test was used to assess the qualitative variables.

\section{Results}

The study population was comprised of 234 patients of which $134(60 \%)$ were men and $95(40 \%)$ were women, who were undergoing renal haemodialysis. Of 234 patients $58 \%$ were unemployed and $15 \%$ had relevant family history. Retrospective review of medical records of patients with chronic renal failure when assessed showed that $82.5 \%$ of the patients were hypertensive and $57.3 \%$ were diabetic. $14.1 \%$ of the patients had other systemic conditions ( Graph1). Two patients had history of renal transplant.

\section{Graph 1}

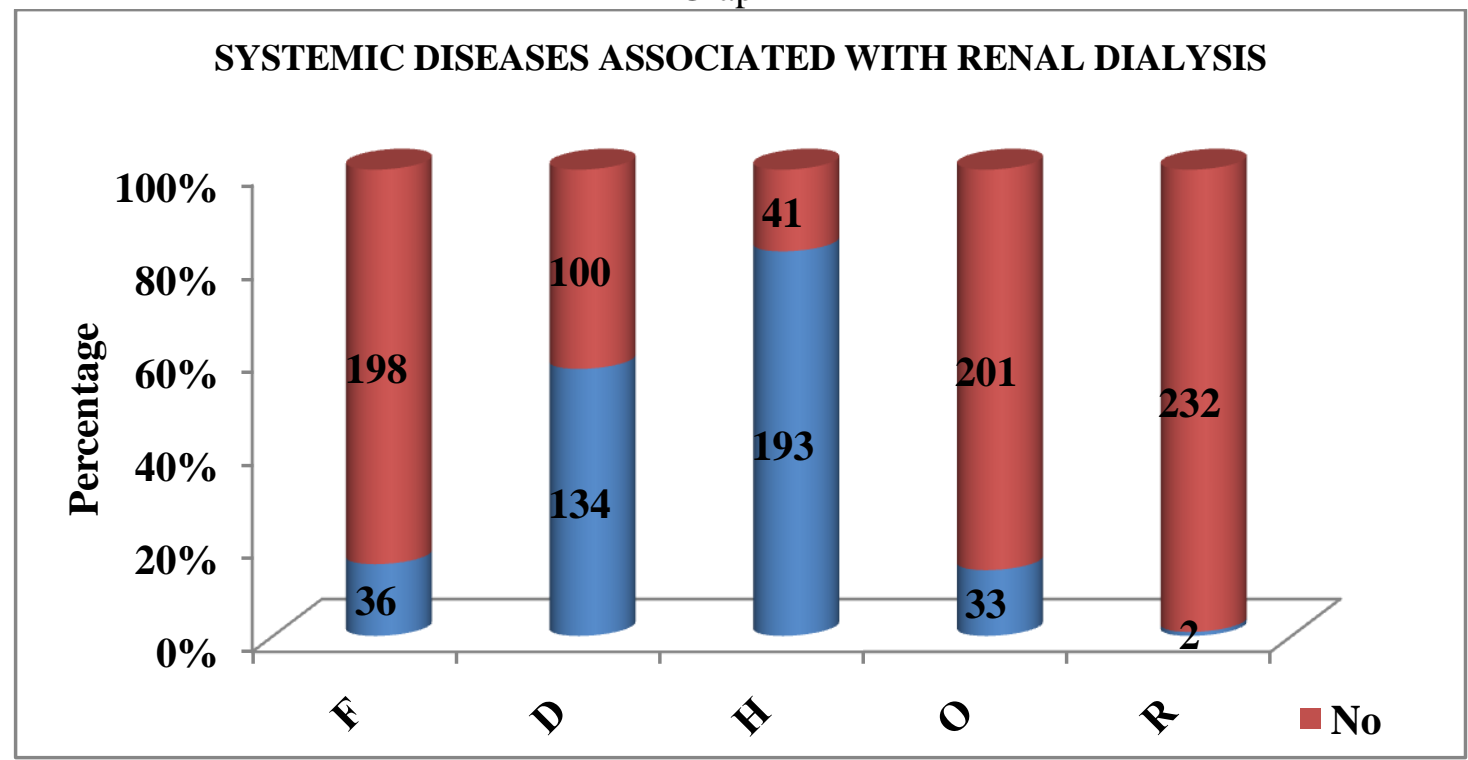

Fa - family history, Dia- diabetes, Hy- hypertension, Oth- others, Re- renal transplant

Oral health status of the patients were assessed using CPITN (Community Periodontal Index Of Treatment Needs). The index showed no significant difference between male and female patients. Among male patient CPITN score $2(65.9 \%)$ was prominent. Among female patients CPITN score $2(64.7 \%)$ was prominent. ( Table 1), (Graph2)

CPITN SCORE VRS GENDER (TABLE 1)

\begin{tabular}{|l|ll|ll|ll|}
\hline & \multicolumn{2}{|c|}{ SEX } & \multicolumn{2}{c|}{ F } & \multicolumn{2}{c|}{ TOTAL } \\
\cline { 2 - 6 } & \multicolumn{2}{|c|}{$\mathrm{M}$} & 7 & $8.2 \%$ & 16 & $7.5 \%$ \\
\hline Score 1 (\%) & 9 & $7.0 \%$ & 55 & $64.7 \%$ & 140 & $65.4 \%$ \\
\hline Score 2(\%) & 85 & $65.9 \%$ & 23 & $27.1 \%$ & 57 & $26.6 \%$ \\
\hline Score 3(\%) & 34 & $26.4 \%$ & & & \\
\hline
\end{tabular}




\begin{tabular}{|l|ll|ll|ll|}
\hline Score $4(\%)$ & 1 & $0.8 \%$ & 0 & $0 \%$ & 1 & $0.5 \%$ \\
\hline TOTAL Score (\%) & 129 & $100 \%$ & 85 & $100 \%$ & 214 & $100 \%$ \\
& & & & & & \\
\hline
\end{tabular}

$\mathrm{X}_{2}=0.788, \mathrm{p}=0.852(\mathrm{NS})$

Graph 2

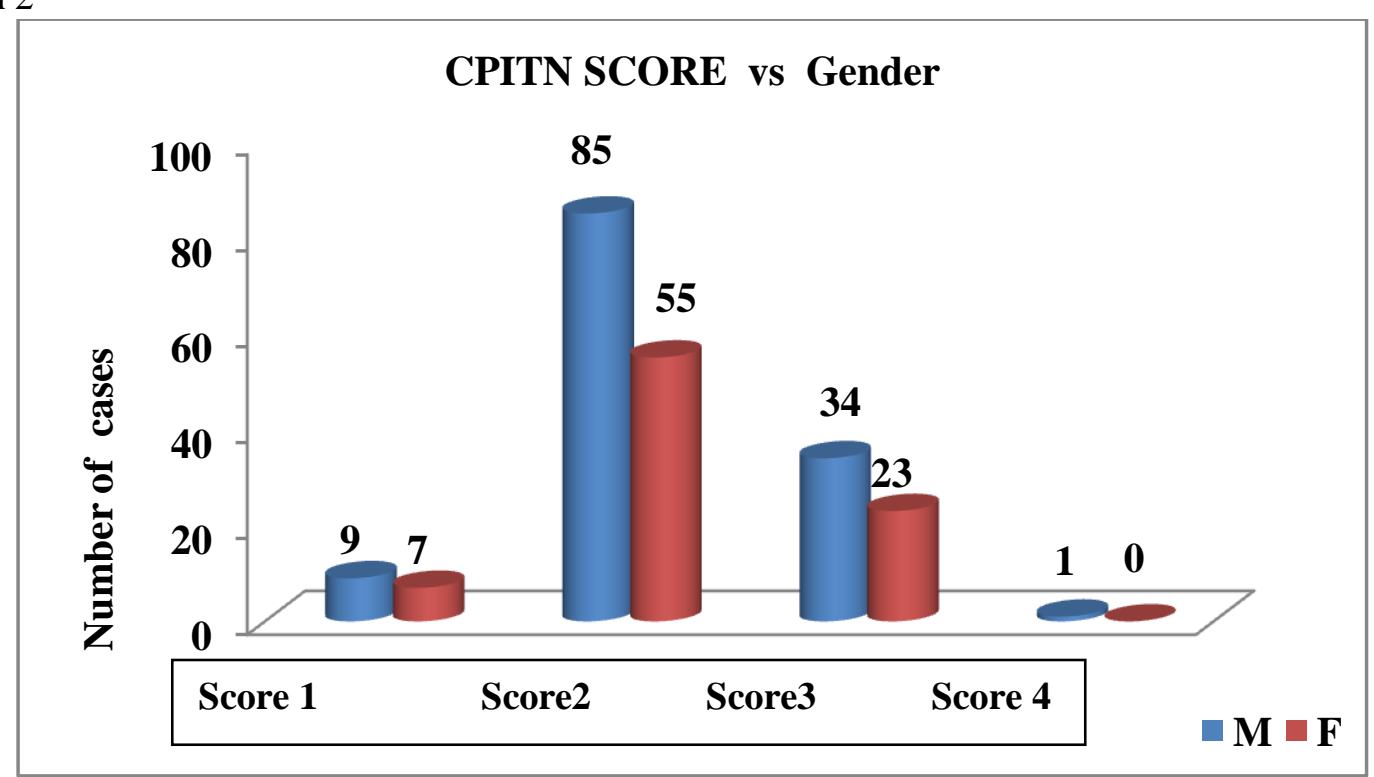

234 patients were divided into 5 age group. (Table 2). CPITN score 2 was seen maximum in all age groups showing that age variation is insignificant $\left(\mathrm{X}_{2}=6.599, \mathrm{P}_{=} 0.883\right)$.

CPITN SCORE VRS AGE GROUP (TABLE 2)

\begin{tabular}{|c|c|c|c|c|c|c|c|c|c|c|}
\hline \multirow{3}{*}{ Score $1(\%)$} & \multicolumn{9}{|c|}{ AGE GROUP } & \multirow[t]{2}{*}{ TOTAL } \\
\hline & $<40$ & \multicolumn{2}{|c|}{$40-50$} & \multicolumn{2}{|c|}{$50-60$} & \multicolumn{2}{|c|}{$60-70$} & \multicolumn{2}{|c|}{$>70$} & \\
\hline & $8.2 \%$ & 6 & $10 \%$ & 1 & $2.4 \%$ & 4 & $8.2 \%$ & 1 & $6.7 \%$ & $7.5 \%$ \\
\hline Score $2(\%)$ & $31 \quad 63.3 \%$ & & $63.3 \%$ & 29 & $70.7 \%$ & & $65.3 \%$ & 10 & $66.7 \%$ & $140 \quad 65.4 \%$ \\
\hline Score $3(\%)$ & $14 \quad 28.6 \%$ & 16 & $26.7 \%$ & 10 & $24.4 \%$ & & $26.5 \%$ & 4 & $26.7 \%$ & $57 \quad 26.6 \%$ \\
\hline Score $4(\%)$ & $0 \%$ & 0 & $0 \%$ & 1 & $2.4 \%$ & 0 & $0 \%$ & 0 & $0 \%$ & $0.5 \%$ \\
\hline $\begin{array}{l}\text { TOTAL Score } \\
(\%)\end{array}$ & $49 \quad 100 \%$ & & $100 \%$ & & $100 \%$ & 49 & $100 \%$ & 15 & $100 \%$ & $214 \quad 100 \%$ \\
\hline
\end{tabular}

$\left(\mathrm{X}_{2}=6.599, \mathrm{P}_{=} 0.883\right)$

The above index shows that the patients were having moderate periodontitis irrespective of their age group. ( $\mathrm{X} 2=0.719 \mathrm{p}=0.033)$, When systemic diseases were assessed, CPITN index showed significant correlation with diabetes. (Table 3). Out of 234 patients, $70.5 \%$ diabetic patients had score 2.

CPITN SCORE VRS DIABETES (TABLE 3 )

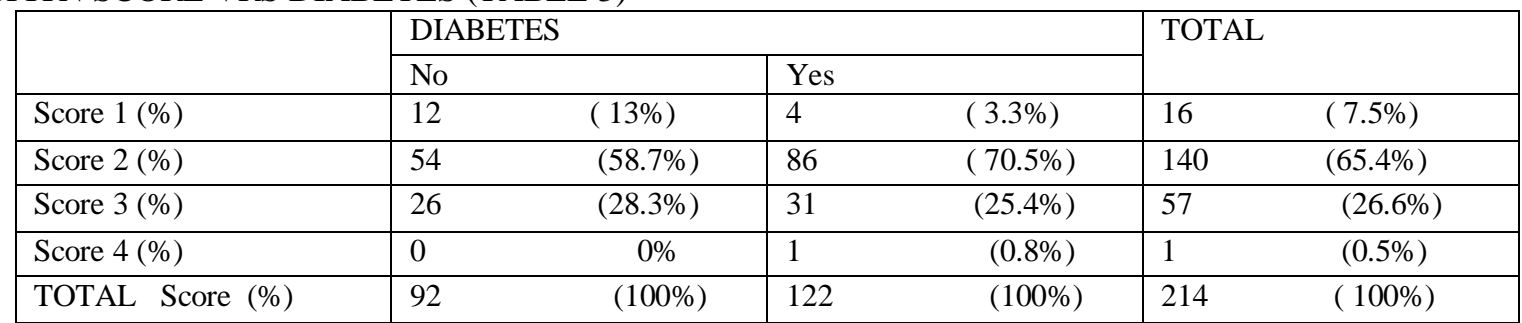

$\mathrm{X}_{2}=8.639, \mathrm{p}=0.035(\mathrm{SIG})$

CPITN index showed significant co-relation with hypertensive patients $\left(\mathrm{X}_{2}=8.639, \mathrm{p}=0.035\right)$ (Table 4). Out of 234, 114 hypertensive patients had score $2(64.8 \%)$. 
Prevalence Of Periodontitis In Hemodialysis Patients

CPITN SCORE VRS HYPERTENSION (TABLE 4)

\begin{tabular}{|c|c|c|c|c|c|c|}
\hline & \multicolumn{4}{|c|}{ HYPERTENSION } & \multirow{2}{*}{\multicolumn{2}{|c|}{ TOTAL }} \\
\hline & No & & Yes & & & \\
\hline Score $1(\%)$ & 6 & $(16.2 \%)$ & 9 & $(5.1 \%)$ & 15 & $(7.0 \%)$ \\
\hline Score $2(\%)$ & 26 & $(70.3 \%)$ & 114 & $(64.8 \%)$ & 140 & $(65.7 \%)$ \\
\hline Score $3(\%)$ & 5 & $(13.5 \%)$ & 52 & $(29.5 \%)$ & 57 & $(26.8 \%)$ \\
\hline Score $4(\%)$ & 0 & $0 \%$ & 1 & $(0.6 \%)$ & 1 & $(0.5 \%)$ \\
\hline $\begin{array}{ll}\text { TOTAL } & \text { Score } \\
(\%) & \end{array}$ & 37 & $(100 \%)$ & 176 & $(100 \%)$ & 213 & $(100 \%)$ \\
\hline
\end{tabular}

$\mathrm{X}_{2}=8.639, \mathrm{P}=0.035(\mathrm{SIG})$

\section{Discussion}

Moderate to severe periodontitis is prevalent in the general population and may be more prevalent in the ESRD population on haemodialysis maintenance therapy. CPITN was used to analyse periodontal status as it further indicated a severity of gingivitis and periodontitis in renal failure patients. The result obtained in the study is similar to the study done by Borawski J et al in $2006{ }^{9}$ which showed that disease was most advanced in maintenance Haemodialysis patients. Renal replacement therapy can affect periodontal tissues including gingival hyperplasia in immune suppressed renal transplantation patients and increased levels of plaque, calculus and gingival inflammation and possible increased prevalence and severity of destructive periodontal diseases in ESRD patients on dialysis maintenance therapy. Also, the presence of undiagnosed periodontitis may have significant effects on the medical management of the ESRD patient.

Oral health status of 234 patients were assessed using CPITN (Community Periodontal Index Of Treatment Needs) which revealed that $0 \%$ of the patients had good oral hygiene $(0 \%), 16$ patients $(7.5 \%)$ had score 1(bleeding during and after probing), 140 patients had score 2 (65.4\%) (presence of calculus or plaque retentive factors ), 57 patients had score 3 (pathologic pocket of 4-5mm), 1 patient had score 4( pathologic pocket of $6 \mathrm{~mm}$ or more). The data obtained in this study is similar to a study done by Farhad Atassi et al in $2001^{10}$, which concluded that periodontal disease is prevalent in renal dialysis patients who showed unacceptable level of oral hygiene and which may increase with the chronicity of the illness. Oshrain et al reported a significant correlation between plaque levels and gingival inflammation in dialysis subjects. ${ }^{11}$ In another study done by Naugle K in $1998^{4}$, severe gingivitis characterized by marked redness, inflammation and tendency to bleed was observed in the sample studied. The renal dialysis sample studied by Brown LJ et al 1989 ${ }^{12}$ showed a $100 \%$ prevalence of mild to moderate gingivitis which is greater than the prevalence of periodontal disease $(85 \%)$ found in general population.

234 patients were divided into 5 age group. (Table 2). CPITN score 2 was seen maximum in all age groups showing that age variation is insignificant suggesting that the patients were having moderate - severe gingivitis, 26.6\% had moderate periodontitis and 1 patient with severe periodontal disease irrespective of their age group. Estimates of the prevalence of periodontitis vary with the clinical criteria used to define disease status; however, the Third National Health and Nutrition Survey (NHANES III) reported a 14\% prevalence of moderate to severe periodontitis in the United States population $>20$ years of age. ${ }^{13}$

When systemic diseases were assessed, CPITN index showed significant correlation with diabetes. Out of 234 patients, $70.5 \%$ of the diabetic patients had score 2 . This shows that periodontitis contributes to generalized inflammation and development of systemic diseases. Periodontitis-related microorganisms spreading into the bloodstream are thought to impair blood rheological parameters - for example, increasing whole blood viscosity, aggregating blood elements, and decreasing blood flow - and thereby significantly accelerate systemic or local diseases. ${ }^{14}$ Patients receiving dialysis are more susceptible to infections because of general debilitation, depression of the immunologic response and masking of signs and symptoms of infection by drug therapy. ${ }^{15}$

CPITN index showed significant co-relation with hypertensive patients. Out of 234, 114 hypertensive patients had score $2(64.8 \%)$. Periodontal diseases in the general population have been associated with both an increased prevalence of atherosclerotic complications. ${ }^{16}$ Atherosclerotic complications including hypertension proceeded by myocardial infarction and stroke are the primary causes of mortality in the ESRD population. ${ }^{2,17}$ Consequently, periodontitis may be a covert but treatable source of systemic inflammation in the ESRD population.

\section{Conclusion}

The ESRD patients on haemodialysis maintenance therapy with periodontitis is medically complex and presents the dental practitioner with several challenges in the management of their periodontal condition. Accordingly, close communication between the patient's dentist and nephrologists is essential to optimize periodontal management. Current approaches for initial periodontal therapy include meticulous oral hygiene 
procedures performed daily by the patient to remove newly formed subgingival plaque in an attempt to alter the subgingival bacterial profile coupled with professional local mechanical root debridement ('root planning') to remove calculus and absorbed bacterial products.

However, the presence of extensive pocket formation associated with severe osseous defects or exposure of anatomical features such as root furcations may inhibit attempts at effective oral hygiene or local root debridement. Therefore, for patients who have not resolved after initial periodontal therapy and who demonstrate adequate levels of plaque control, surgical pocket elimination, either by resection or regeneration, may be indicated. Severe periodontal pocket formation not amendable to surgical intervention will ultimately result in loss of the affected tooth.

\section{References}

[1]. Fergerson CA, Whyman FA, Dental management of people with renal disease and renal transplantation. N Z Dent J 1998;94, 125136

[2]. Craig R.G . Interactions between chronic renal disease and periodontal disease. Oral Dis 2008, Jan 14(1), 1-7

[3]. Kardachi BJ, Newcomb GM. A clinical study of gingival inflammation in renal transplant recipients taking immunosuppressive drugs. J. Periodontol 1978;49;307-10

[4]. Naugle K, Darby ML, Bauman DB, Lineberger LT, Powers R, The oral health status of individual on renal dialysis. Ann Periodontol $1998 ; 3 ; 197-205$.

[5]. Fisher M.A, Taylor G W, A prediction model for chronic renal disease includes periodontal disease. J. Periodontol 2009; 80; 16-23.

[6]. Fisher M.A, Taylor G W, Papapanov PN et al, clinical and serological markers of periodontal infection and chronic kidney disease. J. Periodontol 2008;79;1670-1678.

[7]. Kshirsagar AV, Moes KL, Elter JR et al, periodontal disease is associated with renal insufficiency in artherosclerosis risk in communities (ARIC) study. Am.J.Kidney Dis 2005;45;650-657.

[8]. Kshirsagar AV, Craig RG, Moes KL et al, Periodontal disease adversely affecting the survival of patients with end stage renal disease. Int;2009;75; 746-751.

[9]. Borawski J, Wilczyńska-Borawska M, Stokowska W, Myśliwiec M. The periodontal status of pre-dialysis chronic kidney disease and maintenance dialysis patients. Nephrol Dial Transplant. 2007 Feb;22(2):457-64.

[10]. Farhad Atassi, DDS, MSc, FICOI ,Abdullah R. Al-Shammery, BDS, MSc ,Saeed Al-Ghamdi , BDS . Gingival health among individuals on haemodialysis in a Saudi population, Saudi Dental Journal, Vol. 13, No. 2, May - August 2001.

[11]. Oshrain HI, Mendre S and Mandel ID. Periodontal status of patients with reduced immunocapacity. J Periodontol 1979;50:185-188.

[12]. Brown LJ, Oliver RC and L e H. Periodontal diseases in the U.S. in 1981: Prevalence, severity, extent, and role in tooth mortality. J Periodontol 1989; 60:363-370.

[13]. Oliver RC, Brown LJ, Loe H. Periodontal diseases in the United States population. J Periodontol 1998; 69: 269-278

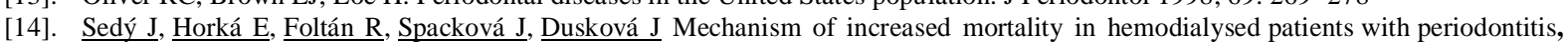
Med Hypotheses. 2010 Feb;74(2):374-6.

[15]. Deykin D. Uremic bleeding. Kidney Int 1884;24:698-705.

[16]. Nadeem M, Stephen L, Schubert C, Davids MR, Association between periodontitis and systemic inflammation in patients with endstage renal disease. SADJ. 2009 Nov;64(10): 470-3.

[17]. Craig RG, Spittle MA, Levin NW, Importance of periodontal disease in the kidney patient. Blood Purif. 2002;20(1):113-9. 